\title{
Anhidrotic ectodermal dysplasia presenting as a pyrexia of undetermined origin in the neonatal period
}

\author{
J. MiLls* \\ M.B., Ch.B.(B'ham), D.C.H., M.R.C.P.(G) \\ Formerly Paediatric Registrar, \\ Redhill and Netherne Group of Hospitals
}

ANHIDRotic ectodermal dysplasia is a heredofamilial sex-linked recessive disease-although in some families a dominant trait has been described. The disease is characterized by anhidrosis, hypotrichosis and hypodentia ; other defects such as the absence of nipples may also be present.

Most of the reports of this condition are on older children and adults brought to light by the discomfort caused by the absence of sweat glands.

Jesperson writing in November 1962 says that as the defects are congenital, intolerance to heat is present from birth and it is therefore surprising that the disease is only rarely reported to be a cause of hyperpyrexia in infants. He suggests, as a possible explanation, that the presence of trivial infections may be easily conceived as a plausible explanation of the frequent attacks of fever in such patients. Jesperson could find only seven cases recorded under the age of 6 months and added three more of his own-the youngest being 3 months old. However, as far as could be ascertained from the literature, no case presenting with hyperpyrexia in the neonatal period has been documented. The following case is, therefore, thought to be of interest and was originally presented at the Paediatric Section of the Royal Society of Medicine in October 1965.

\section{Case report}

This male child was born on 22 December 1964 at full time, a normal delivery, birth weight $7 \mathrm{lb} 2 \mathrm{oz}$. Behaviour normal at first. Only child of unrelated parents. There is no family history of this disease but a right lower facial palsy was noted which is inherited from the maternal side. Three days after birth he became irritable and was found to have a temperature of $100 \cdot 2^{\circ} \mathrm{F}$, which persisted. On examination, he was an oddlooking baby with small eyes, low lying ears, dry 'parchment' skin, and a scaly erythema around the eyes. No hair was present but his

\footnotetext{
* Present address: F/3/9 Model Town, The Mall, Delhi 9.
}

nails were normal and nipples were present. No abnormality could be found in any other system.

Investigations. Blood counts and cultures, urine, stools, urea, nose and throat swabs, cerebrospinal fluid and mother's W.R., all normal.

Despite various antibiotic courses (tetracycline, cloxacillin, penbritin) he continued to spike temperatures of $102^{\circ} \mathrm{F}, 103^{\circ} \mathrm{F}$ (Fig. 1). The

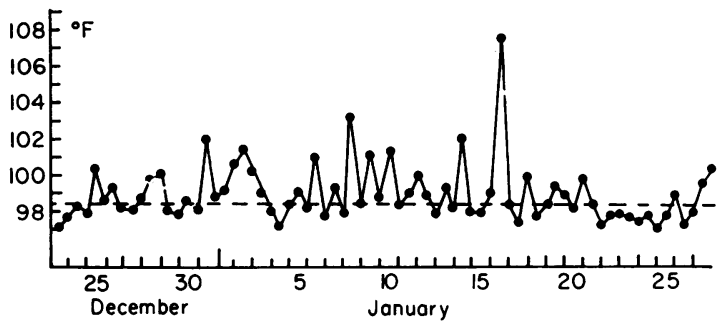

Fig. 1

striking feature, however, was that these pyrexias seemed to be out of keeping with his general well being. On 8 January his temperature was suddenly $105.6^{\circ} \mathrm{F}$ and a few days later $107.6^{\circ} \mathrm{F}$ and the latter hyperpyrexia was associated with a convulsion. Following this episode he deteriorated requiring tube feeding and became fisted, the limbs showed increased tone and he had attacks of opisthotonus. These attacks of opisthotonus were heralded by 'ashen-grey' turns and abdominal distension. At this time a diagnosis of ectodermal dysplasia was entertained and confirmed by X-ray of the jaw (Fig. 2). Later axillary skin biopsies were taken from the patient and control: no sweat glands were found in the patient's tissue.

The baby was nursed in the special care unit; the first room at $80^{\circ} \mathrm{F}$ and second at $76^{\circ} \mathrm{F}$. He was then transferred to a cooler room and made a good recovery. He was discharged home on 30 January 1965 on phenobarbitone $8.0 \mathrm{mg}$ t.d.s. Since discharge he has had several coryzas but 


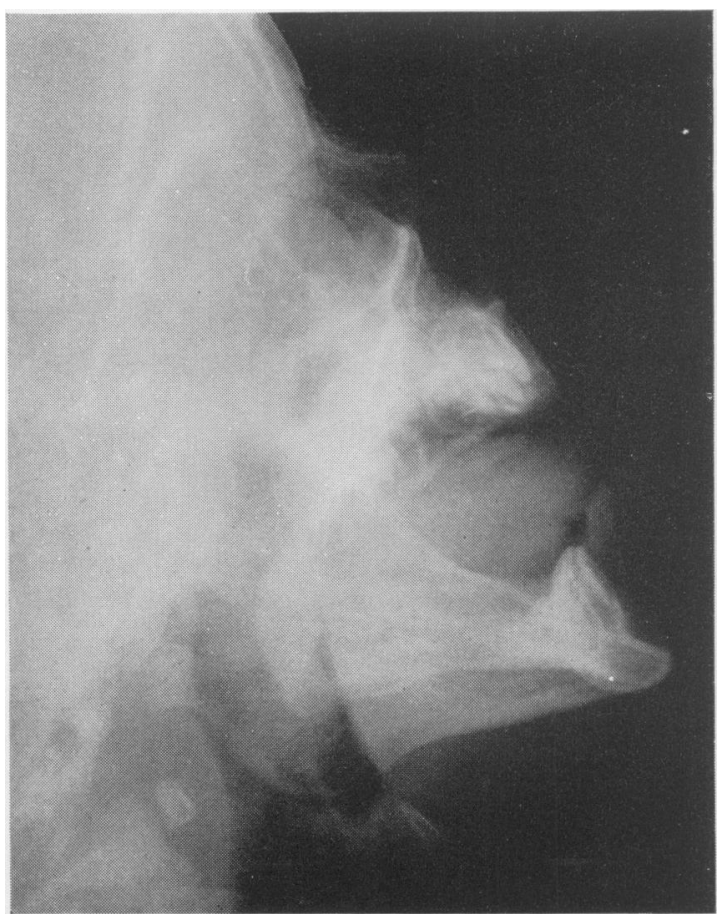

FIG. 2

has not been hyperpyrexial. Physically he has maintained the fiftieth percentile. At the age of 11 months he is beginning to walk. Nails are normal but his hair has grown only sparsely. Teething symptoms have been mentioned by the mother but no teeth have erupted. Recent dental $X$-ray now shows two malformed tooth buds in the lower jaw.

\section{Discussion}

Once infection and cerebral trauma have been excluded there remain a few rare conditions which may present with high temperatures during the neonatal period. Congenital thyrotoxicosis is very rare. More common is the rebound hyper-irritability, which may be associated with hyperpyrexia, of a baby born to a thyrotoxic mother who is on antithyroid treatment. Other diseases are diabetes insipidus, nephrogenic diabetes insipidus and congenital lues. Most of these can be easily excluded. Although it is easy to establish the diagnosis of ectodermal dysplasia the subsequent treatment may not be so simple.

The first and most important problem is the control of the hyperpyrexias. Most patients with this disease are mentally normal; those who are retarded may be so as a result of brain damage following 'febrile convulsions' in infancy. These hyperpyrexias can occur alarmingly quickly: a temperature of $108^{\circ} \mathrm{F}$ in a 3-month-old infant was recorded by Glicklich \& Rosenthal (1959). Another sufferer, a farmer, whenever he went out into the fields took a boy whose sole job was to drench the harvester with two pails of cold water at regular intervals.

Our patient was kept loosely clad in a cotton vest and at home the parents were warned against over-clothing and to give him a tepid sponge at the first sign of any fever. Such patients should not live in the tropics or take vacations in hotter countries during the summer heat.

Besides the dangers of hyperpyrexia, another aspect of treatment is the fitting of dentures. This is important not only for nutrition and for the proper moulding of the alveolar margins but also cosmetically and psychologically, especially when he goes to school. Anodontia is extremely rare but what teeth are present in these cases usually erupt malformed and maloccluded.

Other patients present as psychiatric problems: maladjusted children or attempted suicides, usually following depressive bouts. Besides the discomforts of being unable to sweat the patient has to live with his odd facies-which is ugly; the bridge of the nose is poorly developed and atrophic rhinitis is troublesome. If he has had no dental care his face is even more misshapen: edentulous, he becomes a social outcast. It is important, therefore, to recognize this condition because such patients, requiring as they do much supportive psychotherapy, do far better with the help of plastic and facio-maxillary surgery. It is this treatment that brings back incentive and a new lease of life to these patients.

\section{Acknowledgments}

My thanks are due to Dr P. R. Clay, who not only kindly allowed this case to be presented but also gave much helpful criticism, and to The Royal Society of Medicine in releasing the paper for publication elsewhere.

\section{References}

BOVEN, R. (1957) Hereditary ectodermal dysplasia of anhidrotic type. Sth. med. J. 50, 1018.

Glicklich, L.B. \& Rosenthal, I.M. (1959) Anhidrotic ectodermal dysplasia: use of silver nitrate plate to detect anhidrosia. J. Paediat. 54, 19.

IsAA, H. (1965) Total anodontia with ectodermal dysplasia. Brit. dent. J. 118, 537.

JESPERSON, H.G. (1962) Ectodermal dysplasia of anhidrotic type. Acta paediat. 51, 712.

LipshuTz, H. (1963) Anhidrotic ectodermal dysplasia. J. $A$. Einstein med. Cent. 11, 33.

LORBer, J. (1964) Hereditary ectodermal dysplasia. Proc. roy. Soc. Med. 57, 116.

Malagon, V. \& TRAVeras, J.E. (1956) Congenital ectodermal dysplasia and mesodermal dysplasia. Arch. Derm. 74, 253.

Motulsky, A.G. \& Hechт, F. (1963) Genetic prognosis and counselling. Amer. J. Obst. Gynec. 90, 1227.

Pearson, H.A. \& Cone, T.E. (1957) Anhidrotic ectodermal dysplasia with vascular purpura. J. Paediat. 51, 1957. 